\title{
ROMUALDO ALVES DE OLIVEIRA: a trajetória de um repu- blicano histórico nas lides do abolicionismo (1825-1895)
}

\author{
Emanoel da Cunha Germano*
}

\begin{abstract}
RESUMO: Neste artigo apresentar-se-á a trajetória de um republicano histórico pouco conhecido, mas que fez de sua carreira de publicista e advogado sem formação, umas das mais importantes atuações no movimento republicano e abolicionista no Recife, antes mesmo e após, a formação do Partido Republicano em 1870. Atrelando seu ativismo político em defesa da instalação de um governo republicano democrático e federativo, se destaca pela luta que empreendeu em prol a abolição da escravidão no Recife e a posteriori, Rio de Janeiro. Romualdo Alves de Oliveira é um desses personagens históricos que nos surpreende tanto pelas redes de sociabilidades que procurou tecer, quanto nas mobilizações antiescravistas, no qual era reconhecido por seus contemporâneos do norte ao sudeste do Brasil oitocentista.

PALAVRAS-CHAVES: Movimento social; Republicano histórico; Abolicionismo; Recife.
\end{abstract}

\section{Romualdo Alves de Oliveira: the trajectory of a historical republican in the struggle of abolitionism (1825-1895)}

ABSTRACT: In this article we will present the trajectory of a little-known historical republican, who made his career as a publicist and lawyer without training, some of the most important actions in the republican and abolitionist movement in Recife, even before and after the formation of the Republican Party in 1870. Coupling his political activism in defense of the installation of a democratic and federative republican government, he stands out for the struggle he waged in favor of abolition slavery in Recife and a posteriori, Rio de Janeiro. Romualdo Alves de Oliveira is one of those historical characters that surprises us both for the networks of sociability he sought to weave, as well as in the antislavery mobilizations, in which he was recognized by his contemporaries from the north to the southeast of Brazil in the 19th century.

KEYWORDS: Social movement; Historic Republican; Abolitionism; Recife.

\section{Romualdo Alves de Oliveira: la trayectoria de un republicano histórico en la lucha del abolicionismo (1825-1895)}

RESUMEN: En este artículo presentaremos la trayectoria de un republicano histórico poco conocido, que hizo su carrera como publicista y abogado sin formación, algunos de las acciones más importantes del movimiento republicano y abolicionista en Recife, incluso antes y después de la formación del Partido Republicano en 1870. Uniendo su activismo político en defensa de la instalación de un gobierno republicano democrático y federativo, destaca por la lucha que libró a favor de la abolición esclavitud en Recife y a posteriori, Rio de Janeiro. Romualdo Alves de Oliveira es uno de esos personajes históricos que nos sorprende tanto por las redes de sociabilidad que pretendía tejer, como en las movilizaciones antiesclavistas, en las que fue reconocido por sus contemporáneos del norte al sureste de Brasil en el siglo XIX.

PALABRAS CLAVE: Movimiento social; Republicano histórico; Abolicionismo; Recife.

\footnotetext{
*Mestre em História Social pela Universidade Federal Fluminense. Contato: Rua Marcos Waldemar de Freitas Reis S/N, CEP: 24210-201, Niterói-RJ, Brasil. E-mail: emanoelcunha@id.uff.br. ORCID: https://orcid.org/00000001-6947-4982
} 


\section{Do interior para a cidade do Recife: percursos de um republicano cosmopolita}

No interior de Pernambuco, na primeira metade do século XIX, a comarca de Goiânia era umas das principais áreas de influência econômica e política na história da região açucareira. ${ }^{1}$ Relevância essa dada não apenas pelo volume de produção de açúcar que nela se produzia durante todo período colonial e imperial, mas também pela participação ativa de seus compatriotas, presentes nos principais acontecimentos que conformam a identidade dos pernambucanos. Dentre esses e outros aspectos relacionados a essa cidade interiorana, importantes personalidades históricas nela nasceram. Esse é o caso de Romualdo Alves de Oliveira. Republicano histórico pouco conhecido pela própria historiografia do movimento que advogara por décadas e pelo que registraram as fontes, é sem sombras de dúvidas, um dos precursores do movimento antiescravista em Pernambuco. ${ }^{2}$

Romualdo Alves de Oliveira nasceu no mesmo ano em que o Imperador D. Pedro II veio ao mundo, em 1825, e faleceu na cidade do Rio de Janeiro, por volta de 13 de janeiro de 1895. Sobre sua filiação consta no manual de Sacramento Blake ${ }^{3}$ que foi filho de dona Lourença Alves de Oliveira e Joaquim Alves de Oliveira. ${ }^{4}$ Exerceu várias profissões, desde a de alfaiate até as quais obtivera destaque, sendo elas o jornalismo e advocacia. Ao nos determos nos dados documentados sobre sua trajetória, percebemos que era homem livre e circulou entre a elite política e intelectual de sua província, reconhecendo-se, deveras, como membro dela, passando a atuar fortemente na imprensa local.

Ao mudar da comarca de Goiânia para o Recife passou a publicar impressos de orientação republicana, tomando para si a tarefa de advogar pela liberdade do povo pernambucano, contra a monarquia instituída. Como jornalista, reconhecia o potencial da imprensa na opinião pública da época e, por esse instrumento de comunicação oitocentista procurou participar de redes de sociabilidades que comungassem com os princípios para os quais advogava. Casouse com dona Eufrosina Alves de Oliveira. Sabe-se que desse matrimônio teve três filhos: duas mulheres e um homem. ${ }^{5}$ Como publicista republicano, antes mesmo do surgimento de o Partido Republicano em 3 de dezembro de 1870, na Corte, Romualdo Alves já atuava propugnava seu republicanismo aliado a uma perspectiva antiescravista nos impressos que publicou, entre as décadas de 1850 e 1870.

Participou dos clubes republicanos que se organizaram na cidade do Recife e, posteriormente, como se verá, nos quadros dos republicanos radicais no Rio. Antes de exercer o jornalismo, foi alfaiate. Na divulgação de seus jornais ainda atuou como rábula, e não obstante, 
procurou também se lançar como escritor público. Desta última empreitada, publicou livros de pouco sucesso. Para se lançar ao público era necessário estabelecer redes associativas para que fosse possível ser impressas as suas obras. Neste sentido, foi possível perceber os laços que esse democrata procurava estabelecer com pessoas do governo imperial, chegando a se lançar na carreira política, porém sem êxito.

Ao exercer mais de um ofício, alcançou certo prestígio social e político no espaço público recifense, sendo responsável por uma rica produção de artigos republicanos que circularam em diferentes na cidade do Recife. Possivelmente, no curso desse protagonismo e de seu conhecimento sobre o campo jurídico, conseguiu ter a concessão para advogar pelo Tribunal de Relação do Recife, cuja formação não possuía, mas seria por esta profissão, reconhecido durante toda sua trajetória.

Durante a pesquisa e investigação bibliográfica, percebemos que a historiografia pouco o menciona e quando se remete, a sua trajetória, atribuiu a esse personagem um papel secundário, especificamente, associado a eventos políticos e sociais que resultaram na mobilização de Romualdo Alves. A primeira, despontamos seu papel na defesa da emancipação da mulher e, na segunda frente, a nacionalização do comércio a retalho.

Personagem politizada de sua época, era bastante conhecido por defender os direitos das mulheres aos estudos em medicina, chegando a criar projeto que se concretizasse para o benefício dessa classe, nos idos de 1879 a 1880. Tal debate não foi bem visto pelos políticos pernambucanos, pois não se considerava relevante às mulheres ocuparem tais postos, à exceção de alguns poucos deputados que passaram a apoiar à causa. Romualdo em busca dessa conquista ao mesmo tempo lutava para que sua filha pudesse garantir uma subvenção (ajuda de custo) para estudar medicina nos Estados Unidos ou na Suíça. A situação, algo incomum para época, causou o maior rebuliço nas galerias da Assembleia Legislativa. As circunstâncias se deveram às discussões e embates sobre se tais ideias deveriam tornar-se ou não em projeto de lei pelos parlamentares recifenses. Por ora, os detalhes pormenores desse acontecimento não nos interessam, mas cabe destacar que a presença desse republicano, face à agitação do assunto, preencheu as galerias da Câmara Legislativa da cidade do Recife, no final de 1870.

Quanto à participação deste républico no que tange ao comércio a retalho, esse assunto, bem estudado na tese do historiador Bruno Dornelas, o autor demonstra como a comunidade portuguesa ligada ao comércio procurou manter seus interesses econômicos em Pernambuco através de uma rede de sociabilidade, dentro e fora da província dos tempos da praieira até nos idos de 1870. Deste intenso conflito político que antecedeu o movimento praieiro, o 
pesquisador sustenta, criteriosamente: “A geração da Praieira deixou seus herdeiros, sendo o mais notável de todos Romualdo Alves de Oliveira, redator de inúmeros periódicos". ${ }^{6}$ Não é fortuita essa afirmação, tendo em vista o nome de Romualdo Alves figurar como um dos principais defensores do referido embate que fez a cidade de onde nasceu - Goiânia - apavorar, as autoridades da Corte, quanto de sua repercussão em Portugal. ${ }^{7}$

A origem do conflito político entre portugueses e brasileiros se deveu às chistosas crônicas d'As Farpas, publicadas em Portugal, cujo texto era autoria de Eça de Queiroz e Loureiro e Ramalho, escritores portugueses reconhecidos pela intelectualidade pernambucana. $\mathrm{O}$ conteúdo do texto para além de rebaixar os brasileiros com termos pejorativos, não foi o suficiente. Havia por detrás do texto, a questão da subordinação e precarização dos trabalhadores nacionais, em detrimento aos imigrantes portugueses que controlavam o comércio. Foi contra essa hegemonia que a população da cidade de Goiânia entrou em atrito com os lusitanos, ganhando seus conflitos repercussão nos jornais nacionais e portugueses. Tomando parte dos embates Romualdo Alves para além de criticar tal texto e seus autores, se pronunciou em nome dos seus conterrâneos, por isso, passou a dirigir a folha O Comércio a Retalho (18721875) com João Câncio Gomes da Silva que, segundo Paulo Calvacanti "Foi, sem a menor dúvida, dos órgãos da imprensa periódica da década de 70, o mais vivo e interessante, do ponto de vista ideológico e doutrinário, no debate de temas de economia política, de comércio interno e externo e de questões de política nacional"

Posto esse panorama de ativismo político e social, após consultarmos os impressos políticos produzidos e que mencionam o nosso personagem, podemos traçar uma série de acontecimentos históricos e questões emblemáticas em torno das representações de mundo e expectativas dos republicanos oitocentistas. Neste trabalho de síntese, pretendemos reconstituir parte das experiências que Romualdo Oliveira no Recife do XIX empreendeu, indagando continuamente: quais seriam os motivos de sua ausência nos principais movimentos sociais que conformam o republicanismo oitocentista pernambucano $?^{9}$ Diante desse esquecimento, questionamos, por que personagens como Romualdo caiu nas valas comuns da história? O fato de ser republicano e antiescravista histórico, num período anterior ao movimento abolicionista, seria o suficiente para tirar-lhe às oportunidades de galvanizar lugares sociais de maior destaque? Pequena parte da historiografia regional quando o menciona sustenta partes isoladas de sua historicidade. 
Será que a historiografia nacional teria desprezado suas experiências por ser republicano e abolicionista ao mesmo tempo? Para enfrentar estes questionamentos seguiremos seu percurso nas próximas páginas.

\section{De publicista a tipógrafo: política e circulação de ideias republicanas no Recife (1853-1875)}

No início da década de 1850 , este ano especificamente parecia conturbado, pois era um período de transformação política na sociedade brasileira. Em especial na vida de Romualdo. Pretendia mudar-se da comarca de Goiânia - interior de Pernambuco - para o Recife. É nesse momento em que o encontramos nos jornais da época. Em um deles, obtivemos a informação que em Goiânia acabara de vender sua casa, situada na "rua da Soledade desta cidade". ${ }^{10}$

Estabelecido na capital da província pernambucana, desempenhou um papel histórico de grande relevância ao mundo da imprensa. De fato, além de fomentar uma cultura impressa de textos de orientação republicana, houve momentos em que o mesmo procuraria se lançar como candidato a deputado da região em tela. Não obstante, como era comum na época e, além do mais, por ser republicano, não obteve votos suficientes para o pleito. Através das publicações que fazia circular e de outros jornais de grande circulação, informava concorrer o pleito. É significativo que não deixaria de sofrer perseguições e acusações por parte das autoridades locais, resultado do republicanismo que propunha advogar nos jornais e nas ruas.

Em sua carreira de escritor público produziu significativos jornais políticos. Nestes impressos, a proposição republicana era defendida como melhor modelo de governo, indo contra aos ideários monarquistas que dominavam a cena política pernambucana. Pode-se se afirmar que no período em que os gabirus dominaram a política nacional nesta província, os republicanos históricos - que não tinham a estrutura de partidos como hoje a concebemos -, fizeram resistência aos partidos da Coroa, cuja predominância configurava-se através da alternância política entre conservadores e liberais no poder.

De meados de 1850 para a década de 1860, coube então ao Partido Liberal estruturarse como oposição à hegemonia do partido Saquarema - conhecida pela literatura, como conservadores emperrados - para formar a famosa união que se esboçaria com a formação do Partido da Liga Progressista. ${ }^{11}$ Diante desse contexto conturbado na política nacional, realçar que os republicanos de Recife não se omitiram diante desses impasses é importante, pois acompanharam o desenvolvimento do pacto da Liga Progressista, organizado por políticos liberais, 
outrora conservadores, descontentes com o Partido que atuaram. Nabuco de Araújo e Araújo de Lima, ambos fizeram parte desse grupo político.

Entre realidades e dissoluções, os republicanos históricos da geração da praieira, através da publicação de jornais de cunho republicanos se propuseram cada um a seu modo, instruir e propugnar suas ideias em prol da instauração de uma república federativa, colocandose como oposição aos ideários da política Saquarema que estavam no poder e, nesse mesmo movimento contra os ligueiros, que emergiam como novo grupo na política pernambucana. $\mathrm{O}$ grupo de redatores dos periódicos acima mencionados era pertencente a uma geração de jornalistas que participaram do movimento liberal praieiro (1848-1849), cujo objetivo competiulhes a tarefa de reivindicar as reformas do tempo da Praieira: a reforma constitucional, a defesa de sistema republicano federativo para nação, condenando o fim do sistema imperial.

A ação política dos publicistas republicanos nos revela parte do espírito de luta que inspirou as expectativas dos revolucionários de 1848 na França, atribuída pela histografia local de "Quarante-Huitard". Para os franceses esse movimento também ficou conhecido como Revolução de Fevereiro que derrubou o governo monárquico, instituindo nesse país aquela que é conhecida como a segunda república. O impacto desse evento dialogou com a disseminação de textos republicanos que circularam no Recife, tornando-se de conhecimento dos pernambucanos às expectativas e desejos de lutas republicanas que foram assimiladas pelos revoltosos radicais da Praieira. ${ }^{12}$ Conforme descreveu o historiador pernambucano Amaro Quintas em sua tese de cátedra, apontou que a referida geração de democratas da praieira teve como peculiaridade a responsabilidade de disseminar princípios republicanos franceses nessa parte norte do país. Tais reivindicações estão presentes no Manifesto ao Mundo da Revolução Praieira de 1848, um dos principais documentos que os liberais exaltados exigiam a implantação do sistema federalista e a nacionalização do comércio a retalho. ${ }^{13}$ Relembre-se que Romualdo Alves, segundo Bruno Dornelas, é um dos herdeiros desse movimento. Liberais exaltados, digam-se homens públicos que publicavam e defendiam a república.

A distinção entre os republicanos para com os liberais ou conservadores, passa a ser bem delineada nessa época, quando parte do programa da Liga Progressista acena para as divergências das reformas que desejavam para a província. Os partidos da Coroa eram categóricos quanto à permanência do regime imperial brasileiro. Justamente, nesse ponto, a distinção entre ser republicano ou monarquista se esboçava, tendo em vista que os primeiros arguiam pelo fim de um governo baseado em distinções e hierarquias. A soberania da nação competia ao Povo e não a um imperador, defendia os republicanos. 
Nos periódicos dos republicanos da geração quarentiotista é presente a defesa de um governo político que abrangessem toda a população, justificando que numa república a soberania popular deveria prevalecer sobre a monarquia constitucional. Tais contestações sinalizam como jornalistas procuraram disseminar um republicanismo que precede à Praieira mais ganha mais força após aquele momento que a historiografia do século XIX passaria a denominar "período de calmaria" do Segundo Império. ${ }^{14}$ Tanto o partido liberal, como o conservador tinham suas peculiaridades, porém era certa à famosa indistinção entre ser um gabiru e um praieiro, não sendo infundada à máxima que se tornara popular entre os partidos da Coroa, bem delineados, na tese de Ilmar Mattos em seus estudos sobre o Brasil Império. ${ }^{15}$

As reivindicações em torno da reforma da constituinte, comercialização a retalho, a descentralização da província, a defesa de ideias emancipacionistas foram demandas que os republicanos procuravam assegurar no campo da imprensa. Nesse espaço de sociabilidade participaram também dos eventos políticos nas ruas, como na formação de clubes e sociedades, publicando periódicos políticos que se propunham a explicar os malefícios do governo vigente e os benefícios que a república possibilitaria aos brasileiros.

Não deixa de chamar à atenção do público leitor a maneira que procuravam convencer seus leitores a apoiar a forma do governo republicano. Segundo Bignotto ${ }^{16}$, em seus estudos sobre as origens da república, existiram cinco matrizes do republicanismo na sociedade brasileira: a romana, a italiana, a inglesa, a francesa e norte-americana. As abordagens dessas tradições políticas quando discutidas por alguns jornalistas republicanos estavam atreladas tanto aos valores públicos, quanto às noções de virtude política, cidadania, liberdade, igualdade e soberania popular. De certo, a noção matriz é dada porque, acredita o autor que tais modelos indicam a originalidade dessa tradição que, ao mobilizar tais conceitos, atualizam a compreensão dos seus significados, a partir dos desafios de seu próprio tempo. A historiadora Heloisa Starling, em um dos capítulos na referente obra de Bignotto, ao explicitar sobre a matriz norte-americana, destaca a forte existência dessa matriz na América portuguesa entre os séculos XVII e XVIII. ${ }^{17}$ Starling, neste texto, demonstra como através de movimentos políticos o léxico das cinco vertentes apontadas circulava nesse lado do atlântico desde o período colonial. Embora, nem sempre vinculados, esses movimentos são vestígios e evidências que demonstram a forte relação de cruzamento dessa herança do republicanismo com as linguagens política do século XIX brasileiro.

A trajetória empreendida por Romualdo Alves de Oliveira, em conjunto com outros profissionais liberais ${ }^{18}$ nos provam que o republicanismo dos tempos da colônia e posterior a 
esse movimento estava bastante vívido e fora empreendido por homens e mulheres letrados na província pernambucana. Acreditamos que essa linguagem republicana, assim como as da província de Minas Gerais "pode ser vista como um conjunto de discursos e práticas que caracterizam a atividade política em determinada época", arriscando-se na construção de "uma criação histórica, sujeita à constante elaboração e desenvolvimento, em sintonia tanto com os acontecimentos quanto com as atitudes dos indivíduos e grupos, cujos propósitos ela define" como bem definido na dissertação de Luciano Moreira em seus estudos sobre os republicanos na província de Minas Gerais. ${ }^{19}$

Dentre as múltiplas abordagens do republicanismo trabalhadas pelos "quarantehuitard" em seus jornais, interessam àquelas que se voltaram às questões antiescravistas no Recife, logo a partir da segunda metade do século XIX. Esse debate possibilitou a compreensão de como se articularam, desde suas ocupações, reuniões, participação em mobilizações de ruas, como a participação ativa desses républicos em redes associativas, perante as atividades políticas que eram divulgadas em seus jornais republicanos.

$\mathrm{Na}$ história social e política do movimento republicano em Pernambuco, raramente encontramos na historiografia a atuação de republicanos históricos nos eventos que conformam a história pernambucana, quem dirá da articulação que esses grupos empreenderam e registraram sobre os intensos conflitos no Recife. A imprensa republicana do século XIX, no Recife e as demais províncias brasileiras, estão para nos dizer e contribuir muito sobre a percepção que tais grupos pensaram e refletiram sobre a sociedade oitocentista. É claro que alguns trabalhos na área procuraram dar atenção a estes democratas recifenses, destaque-se a tese de doutoramento do professor brasilianista Marc Jay Hoffnagel ${ }^{20}$ e a dissertação de mestrado de Flávia Bruna Ribeiro, ${ }^{21}$ trabalhos importantíssimos para compreendermos como o republicanismo ganhou enraizamento na província. Contudo, diferindo da periodização de ambos que tomam como marco a geração de políticos republicanos já após a formação do Partido depois de 1870, concentramos nosso objeto numa geração precedente, acreditando ser relevante destacar a atuação específica de um destes indivíduos letrados que tomou a responsabilidade de difundir os ideários republicanos, em um momento em que a sociedade brasileira atravessava grandes transformações.

Tomar a trajetória de Romualdo Alves não foi um ato fortuito, mais sim justamente por considerá-la uma carreira marcada por uma rica produção intelectual que desenvolveu, como também pelas intensas relações sociais e políticas que procurou estabelecer na sociedade vigente. Com isso, acreditamos que exercer diferentes carreiras no século XIX, foi uma 
importante estratégia de sobrevivência que a população letrada e livre, não pertencentes aos quadros dos governos monárquicos, exercia. Principalmente, os moradores das zonas urbanas e periféricas das grandes províncias do país. E Recife, região representativa nesse cenário, tinha nessas regiões oportunidades de trabalho diversas, onde a disputa pelo mercado de trabalho era constante entre a população livre e escrava.

Numa sociedade marcada por hierarquias, ser livre e letrado, amenizaria o quadro de condições degradantes em que vivia a maior parte da população brasileira. Para os jornalistas pernambucanos fazer do publicismo seu ganha-pão, quer seja na produção de divulgação de seus conhecimentos, como a alternativa de traduzir livros estrangeiros para língua pátria, foi possivelmente uma boa saída. ${ }^{22}$ Romualdo Alves foi um deles: ao mesmo tempo em que redigia jornais, foi também tipógrafo, chegando ainda a publicar livros. As tipografias que dirigiu no Recife, foram: O Brado do Povo (1854-1856), O Comércio a retalho (1872-1873) e, posteriormente d'A Luz (1873-1875). ${ }^{23}$ Nesses jornais em que foi tipógrafo e redator ao mesmo tempo, interessa-nos a parte em que este republicano denunciava a sociedade escravista em que estava imerso, enfatizando seu republicanismo abolicionista.

Dos republicanos abolicionistas que a historiografia brasileira, pouco a pouco vem trazendo a lume, a figura de Luís Gama é a mais conhecida entre nós, porém quando procuramos reconhecer outras trajetórias de ativismos que dialogam com a do paulista, pouco a historiografia tem conhecimento. Romualdo Alves de Oliveira é um desses sujeitos, pois nas duas frentes - republicanismo e antiescravismo - protagonizou ativismo político. Diante da pesquisa, sabemos que seu antiescravismo é possível de ser delineado já na segunda metade do século XIX. A partir de quando? Do momento que participou de uma das primeiras sociedades emancipacionistas da província de Pernambuco, em fins de 1859, e foi no seu jornal republicano $O$ Democrata (1857-1859) que sinaliza seu posicionamento. ${ }^{24}$ Intitulada “Associação de Socorros Mútua e Lenta da Emancipação dos Captivos" que funcionou entre 1859 a 1862. Ao congratular sua criação, um dia após a sua instalação, registrou o momento de júbilo, declarando que estavam presente mais de 300 pessoas. Em seu discurso antiescravista, anunciou "Existindo o cancro da escravidão na terra, não podia deixar de repercutir o generoso movimento da abolição; e de efeito, criaram-se associações em Minas, Corte e Bahia, e entusiasmo-me dizê-lo - aqui”. ${ }^{25}$ Romualdo para além de participado desta sociedade, transcreveu no jornal, a longa poesia abolicionista que recitou no dia, competindo-lhe registrar, historicamente toda aquela efusão que mobilizara esse acontecimento não singular, mas como podemos notar pluralizado, que estava ganhando novos rumos no Brasil oitocentista. 
Situemos que após a extinção do tráfico negreiro em 1850, as diferenças entre ser emancipacionista ou abolicionista passariam a ser definidas, na medida em que a propriedade escrava era definida pela perspectiva gradualista ou discutiam a ruptura total do desmonte da instituição escravista. Isso não significa que ser emancipacionista ou abolicionista fosse algo coeso, até mesmo antagônico nos modos em que se concebia e pensava a escravidão, mas sim que eram heterogêneos em suas lógicas de sentimentos. Esse comportamento incide sobre os republicanos deste período, podendo-se perceber que essas características estão intimamente relacionadas, por exemplo, a Romualdo de Oliveira e a outro colega seu, o professor negro de primeiras letras Luiz Ciríaco da Silva, ambos os redatores são republicanos e defensores do fim da escravidão em seus jornais. Diferentemente dos republicanos de orientação emancipacionista da pecha do repúblico Antônio Borges da Fonseca, do poeta João de Barros Falcão de Albuquerque Maranhão e, do político, Afonso de Albuquerque Melo que tinham escravos e eram defensores da perspectiva gradualista da emancipação, ou seja, opostos a abolição total e, caso fosse esse concedido, eram da opinião da necessária indenização aos seus donos. Dessa maneira, podemos inferir que essa lógica de sentimento nos dar a dimensão de que nem todo republicano era abolicionista, mas grande parte era emancipacionista, tal como é definido e compartilhado pela geração de republicanos positivistas de 1870 , como exposto na dissertação de Flávia Ribeiro.

Todos os cinco jornalistas, acima mencionados, faziam parte do que viemos chamando ao longo do texto, uma rede de sociabilidades. A interligação de seus nomes é possível de ser flagrada na maioria dos jornais republicanos do Recife para os quais analisamos. Seus ativismos são concomitantes, pois fazem parte de uma mesma geração que atuavam na imprensa com uma linhagem política, cujos símbolos republicanos, procuravam construir representações em busca da liberdade e igualdade da população, parte componente de uma aspiração por uma sociedade democrática que remontava a dos líderes do movimento revolucionário de 1817 a 1824. Não estranha quando os jornais republicanos nos marcos temporais que cobrem nossa pesquisa sempre mencionarem a figura de Antônio Borges da Fonseca. Borges da Fonseca era o elo que os ligava e fazia permanecer viva a esperança desse sentimento revolucionário. É raro, não ler esses periódicos e sempre ver Borges mobilizado nas folhas da geração "quarante-huitarde".

Retornemos ao jornalista Romualdo que fez circular no Recife em torno de sete periódicos no período que essa pesquisa se propôs a investigar, ou seja, de 1850 a 1875. Empunhando sua bandeira antimonárquica, através de linguagem de fácil acesso e por preço módi- 
co, diferentemente, daquelas de grande circulação, as matérias que esse republicano ressaltou seu posicionamento abolicionista são bastante ilustrativas de seu ativismo político e social, tal como pontuaremos. ${ }^{26}$

Na seara de escritor público de impressos fez seu nome, pois com produções de cunho literário, político, crítico e jocoso tratou de assuntos dos mais variados concernentes ao campo econômico e político da nação que se consolidava seu império.

No marco temporal que cobre a presente pesquisa, destaca-se a ordem cronológica de sua produção, em 1850, foram três jornais: O Artista Pernambucano (1853) do qual não dispomos sua materialidade, O Brado do Povo (1854), O Democrata (1857-1859). ${ }^{27} \mathrm{Na}$ década seguinte, o encontramos escrevendo como colaborador nos jornais pernambucanos, como Diário de Pernambuco, Jornal do Recife, etc. Ver as capas de periódicos de Romualdo Alves de Oliveira, publicados na década de 1850 (fig. 1 e 2).

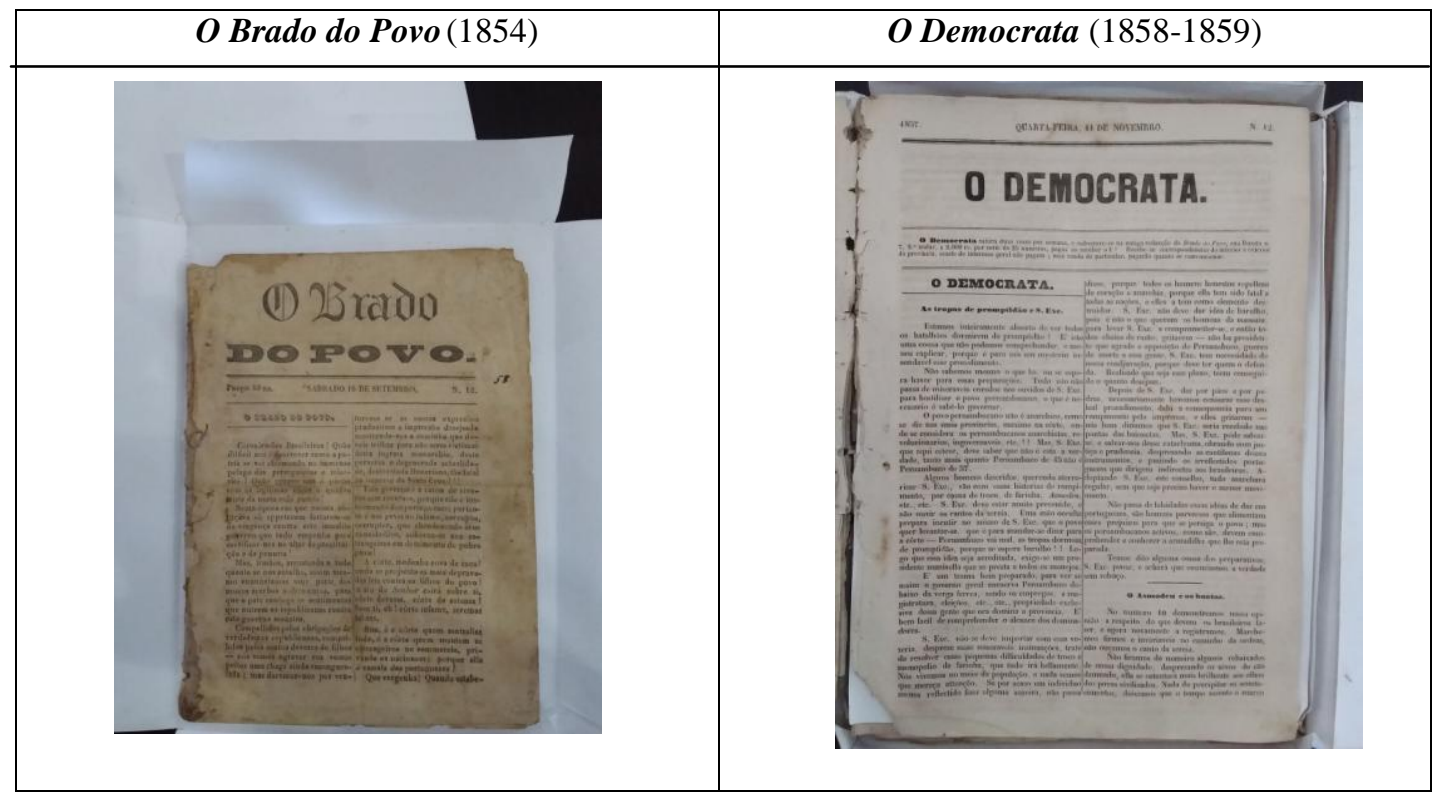

Percebemos que na década de 1860 passou a se dedicar inteiramente como rábula na defesa da população livre e cativa para qual advogava gratuitamente. Nessas idas e vindas às salas da tribuna jurídica, teve tempo de ir a Corte algumas vezes, como aquela que fez para conseguir a liberdade de Pedro Ivo, o paraense que havia participado dos eventos da Cabanada. Seguindo a ordem cronológica dos jornais organizados e publicados por Romualdo, ressaltamos A República (1871), periódico que circulou durante seis meses no Recife.

A República vem a lume, logo após o advento da formação do Partido Republicano na Corte em 3 de dezembro de 1870. A República circulou de maneira irregular, era publicada 
aos domingos, possuía o formato de quatro páginas, cuja produção perfaz um total de 14 números. Em seguida, é a vez da República Federativa (1872-1873) de mesmo formato que a anterior, carregava em seu frontispício o subtítulo: "é órgão do clube Republicano no Recife". Em uma dessas últimas empreitadas como chefe-redator, com A Luz: periódico republicano (1873-1875) se uniria ao amigo de sua geração: Luiz Ciríaco da Silva, professor de primeiras letras para travar embates no que concerne tanto as questões da regiões como trataram do abolicionismo. Ver os jornais de Romualdo Alves de Oliveira, publicados na década de 1870 (fig. $3,4$ e 5$)$.

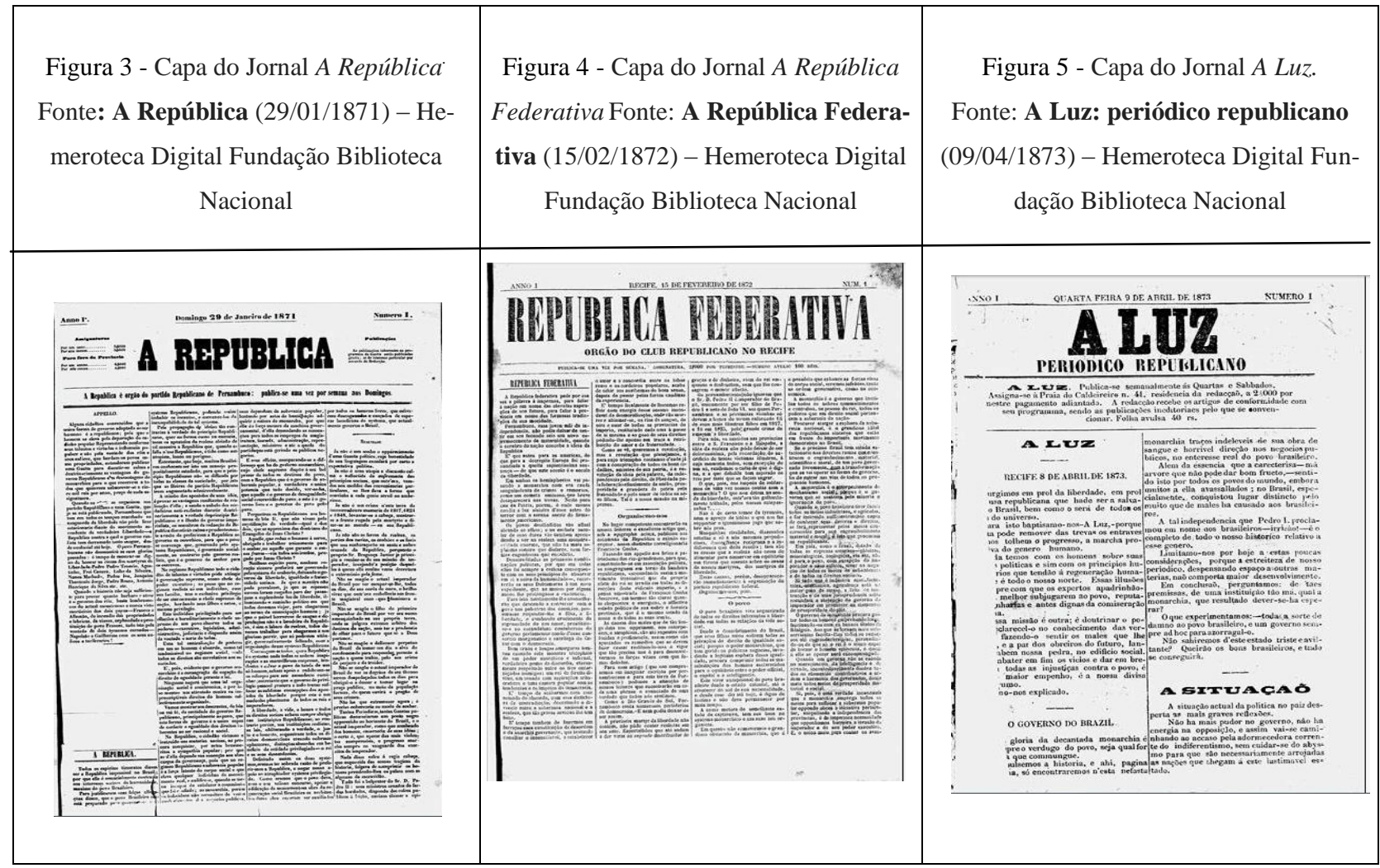

Ressalta-se alguns elementos importantes destes impressos: A República cumpriu a função política de congregar o máximo possível de membros do clube de republicanos, dialogando assim com as entidades centrais da capital federal do Rio de Janeiro. Com a República Federativa: Órgão Club Republicano no Recife vários artigos se responsabilizarem pela instrução do regime, propondo para além da defesa do republicanismo à abolição da escravatura. É o que pode ser lido em um dos artigos: “calcando desaforadamente a lei, vivem reduzido à escravidão cidadãos desse país, brasileiros natos, que pela constituição e leis desse império tinham o direito de ocupar até os mais elevados cargos do estado, e cujo número alcança talvez a um milhão". ${ }^{28}$ A Luz, ao abordar “Abolição total da escravidão no Brasil” propugnou 
que essa causa humanitária seria tarefa daqueles que se consideravam verdadeiros republicanos. Do contrário, seria contradição.

Declarando sua abolição arguia numa de suas matérias: "Não podemos, nós os verdadeiros republicanos, mostrarmos satisfeitos, vendo ainda continuar a escravidão no Brasil". Procurando ir além, o redator afirmava que compactuar com o escravismo não seria característica advinda de seu grupo, sentenciando que seus leitores não deviam "recuar diante de preconceitos e mesmo de perseguições" na defesa da liberdade. ${ }^{29}$ Esse sentimento abolicionista fazia parte da propaganda dos republicanos que propugnavam há décadas pela liberdade, seja dos escravizados como de todo povo brasileiro. Como opositores dos partidos imperiais enfrentaram uma hercúlea batalha de impressos que seus insistiam, a todo instante, em criminalizar o conservadorismo dos monarquistas e da condução política de D. Pedro II. Ao prever as poucas ações de liberdade do ventre livre que o governo monárquico pouco avançava com a Lei de 28 de setembro de 1871, prescrevia "A liberdade há de vencer, e a abolição total da escravidão no Brasil há de abrir uma nova era para futuros vindouros". 30

\section{A política e o jurisdicionalimo como palcos de ação e mobilização}

Homem de vários ofícios, Romualdo não apenas foi jornalista, também tentou se tornar deputado provincial, e de cabo, advogou em causas criminais e cíveis. É possível encontra-lo aliando a sua profissão de redator com a de advogado já por volta de 1860 adiante. ${ }^{31}$ Sua atuação na advocacia é vasta, vai de 1860 até 1890. Dado o mapeamento, registramos um banco de dados onde consta sua participação nas bancas do Júri como advogado de dezenas de brasileiros, presentes nos jornais pernambucanos e do Rio de Janeiro.

Vez em quando é possível destacar a memória que ele procurava constituir de si pelos próprios impressos. Isso, nos momentos que ele procura se eleger, e na sua apresentação ao público, fazia publicar matérias nos jornais locais sobre sua crença republicana desde a juventude e como os representaria na Câmara dos Deputados. Não era homem de lastro, era republicano e por isso, é claro das vezes que tentou, não venceu. É importante notar que tais narrativas de si trazem de certa forma um risco de parcialidade. Uma vez que é destacada não só a imagem que o mesmo constrói, mas também dos argumentos e recursos por ele instrumentalizados na intervenção de sua candidatura nos pleitos em que tentou se eleger como deputado republicano. 
Encontramos Romualdo tentando conquistar, algumas vezes, vaga de deputado nas eleições distritais da província. ${ }^{32}$ A primeira delas é nas eleições de novembro de meados de 1856. Quem dá essa informação é o historiador da "Imprensa Pernambucana” Luiz do Nascimento que teve acesso a um maior número de exemplares do impresso Brado do Povo na década de 50 do século XX. Nascimento em suas leituras, havia lido matérias nas quais esse democrata solicitava aos seus leitores e leitoras votos a favor da chapa de Borges da Fonseca para as eleições de 7 de setembro daquele ano. Contudo, alguns meses depois, Nascimento menciona que Romualdo "ele próprio candidatava-se a eleição de 2 de novembro, pelo círculo de Olinda". ${ }^{33}$ A segunda vez que tentou se eleger, e encontramos sua apresentação, é a partir de 1878. No ano seguinte, em outra conjuntura política, é possível encontrá-lo tentando novamente, angariar votos em 1879. O jornal O Diário de Pernambuco fez circular matéria sobre sua candidatura, onde frisou "Sou republicano intransigente, porém entendo que tenho direito de pedir aos eleitores pernambucanos, para que me elejam deputado provincial". ${ }^{34}$ Por mais que tentasse, sempre o vemos derrotado, pois na província os republicanos, ao encampar disputas com os partidos monárquicos, quem sempre vencia, eram os últimos.

No campo jurídico, logrou maior reconhecimento. Sem ter estudado o curso jurídico, decidiu advogar em diferentes tipos de causas no Tribunal do Recife, recebendo com isso um título de provisionamento pelo Tribunal da Relação de Pernambuco em 1860 para atuar nessa área. Desse ofício, sabemos que foi autodidata. Como costumava se mostrar interessado em diversos assuntos políticos nos jornais que redigiu na década precedente, o do campo jurídico era um dos que mais lhe fascinava. A capacidade retórica de Romualdo e de seu conhecimento era respeitada pelos colegas da área jurídica.

Advogou sem a formação de bacharel, defendendo dezenas de réus para o qual a maior parte era oriunda das camadas mais pobres da sociedade. Esses indivíduos incluíam uma ampla variedade de grupos populacionais, tais como encontramos na seção dos júris nos jornais recifenses: escravizados, padeiros, pedreiros, cocheiros, caixeiros, marítimos, calafates. Pelo perfil deste público, a relação que este republicano teceu corrobora que circulou por esferas sociais distintas, tendo sua trajetória marcada por diferentes correntes teóricas do direito de sua época, para qual recorria as suas noções de direito para conquistar à absolvição de seus réus. ${ }^{35}$

Não pretendemos nos debruçar sobre tais correntes neste trabalho, mas elas merecem uma análise mais aprofundada em trabalhos futuros por ser através do uso da retórica que os advogados oitocentistas expunham tais ideias, não deixando de recorrer a elas para vencer os 
casos que defendiam nas tribunas do júri. O modo como defendia a população pobre ou cativa que não podia pagar é notória nesse sentido, pois sempre noticiava que "sendo pessoa pobre defende grátis", desde os casos classificados como civis quanto criminais. ${ }^{36}$ Ao decidir sair de Pernambuco no segundo semestre de 1883 , foi morar na Corte. Tal decisão, não significou que deixaria de atuar no republicanismo do Rio de Janeiro, pois muito mais radical continuou, se engajando nos órgãos e clubes democráticos da cidade, tendo em vista que sua presença é forte nos ciclos republicanos radicais da capital carioca.

Com a Revolta do Vintém os conflitos gerados pelas manifestações públicas nos finais de 1879 e no ano seguinte, punham em cena novos atores e espectadores que se organizavam para mobilizar à população que revoltava pelo aumento do preço dos bondes. Esse momento inaugura, segundo Sandra Lauderdale Graham, uma nova cultura política. Tais reivindicações procuravam garantir o povo se organizar por meio de clubes, meetings e manifestações públicas. Esse acontecimento histórico é considerado como um divisor de águas, segundo a historiadora já mencionada, pois envolveu vários projetos e expectativas da multidão, afinal, como faz parte de um contexto de mudanças estruturais não é um acontecimento exclusivamente relacionado ao aumento de passagens. Nos bastidores desses eventos, a articulação das principais lideranças republicanas do Rio de Janeiro, esteve atenta ao seu processo, pois através de impressos e conferências de seus membros, a historiadora Cláudia Santos nos brinda com seus estudos sobre essa face pouco explorada do protagonismo que envolveu o "Republicanismo e abolicionismo após o Vintém". ${ }^{37}$ Cientes que há republicanos nesse quadro de manifestações políticas e sociais, tais eventos passariam a ocorrer com maior frequência através de passeatas e meetings, cujas lutas à sociedade se viam excluídas da participação no sistema político vigente. Esses embates nos mostram como a rua era ressignificada, como percebeu a historiadora Maria Thereza Chaves de Melo. ${ }^{38}$

Nesse processo de cultura democrática no final do Império, há o surgimento de dezenas de pasquins que passam a inundar a cidade carioca. Quem analisou esse surto pasquineiro foi Rodrigo Cardoso S. de Araújo em sua dissertação que virou livro, chegando a demarcar a revalorização política praticada por esses impressos em diferentes espaços públicos. Para Rodrigo Cardoso, "os pasquins, que circularam nos primeiros anos desta década, tiveram um papel importante neste processo de revalorização simbólica do papel político concernente à sociedade civil". ${ }^{39}$ Nos bastidores dessa produção de jornais, Romualdo Alves lutava persistentemente por um governo democrático, assim como faziam os pasquins republicanos na capital do Império. Por meio de suas convicções republicanas, não deixou de publicar textos 
para qual, reiterava, a importância da população aderir aos princípios democráticos em prol de seu posicionamento de abolição imediata, tal como vimos. Em suas conferências, é possível lê-lo com seu republicanismo de outrora, convocando a participação do povo nos movimentos de rua, seja contra destituição do império brasileiro em prol a um regime republicano democrático, tal qual defendiam os republicanos radicais da Corte. ${ }^{40}$

Ao tomar numa de suas palestras "As palavras como armas" para defender aquilo que propugnava, considerava que a liberdade dos escravizados há tempos deveria ser efetuada. ${ }^{41}$ Seu engajamento nos clubes republicanos, explorou o máximo das reuniões que existiram para, por meio desses espaços de diálogos e redes de sociabilidade, conquistar apoio político. Na pesquisa realizada, encontramos Romualdo Alves presente no Club Tiradentes, cujo presidente era o poeta Mathias Carvalho. ${ }^{42}$ Obtivemos essa informação da presença do republicano abolicionista pernambucano, neste clube, através do Diário de Notícias. No Clube participaram Quintino Bocaiúva, dentre outras figuras de proa do abolicionismo da província do Rio de Janeiro, como "Vicente de Souza, Luiz Nóbrega e Cyro Azevedo, José do Patrocínio, dentre outros". 43

O desaparecimento de Romualdo na imprensa, no final de 1880, ocupou certa preocupação na imprensa fluminense. Em 16 de novembro de 1888, alguns meses após da Lei Áurea, o jornal Diário de Notícias com alegrias despontava que estava vivo "um dos ornamentos do foro e das conferências abolicionistas". Noticia-se ainda que "Romualdo bem se podia ter mudado desta para melhor, empregando o meio condenado pelo nosso colega Eloy, o heróe Figueiredo Coimbra e outros inimigos do suicídio", visto que, vários suicídios estavam acontecendo na cidade do Rio. Sobre esse último assunto, ele não é foco de nossa matéria. Mas o que é fundamental é que este artigo enfatizava "o esquecimento... do Romualdo". Provavelmente, era um dos seus amigos da imprensa, dando vivas ao republicano histórico que se encontrava na propriedade de seu genro no "hotel Familiar Sapucaiense". ${ }^{4}$ Dado seu sumiço, alguns jornalistas sentiram sua falta, pois sem ao menos escrever "uma linha que tranquilizasse seus amigos", declarava o redator: "é impossível que Sr. Romualdo não tivesse lido as notícias declamatórias sobre a sua morte provável". ${ }^{45}$ A Gazeta de Notícias também tratou do mesmo assunto. Em matéria do dia 24 novembro, na seção intitulada “Apareceu”, informava que as folhas da cidade tem noticiado o desaparecimento do republicano abolicionista, julgando-se que ele tivesse se suicidado. Registrava-se que estava na Vila de Sapucaia, como se vê presente na Gazeta de Sapucaia, publicada no dia 22 corrente. $^{46}$ 
Até aqui, procuramos remontar a fascinante trajetória empreendida por esse republicano. Por meio dessa incursão, percebemos como o historiador se depara com dificuldades em fazer tais análises do ponto de vista documental. Apesar disso, é possível recompô-la. Logo, conhecer as atividades profissionais que exerceu e o contexto social e político de sua época, tal como, seus deslocamentos, foi possível destacar algumas breves considerações baseadas na própria narrativa dos impressos que esse republicano histórico produziu. Também é possível achá-lo presente nos relatos de seus contemporâneos, estes últimos, localizados por onde passou e deixou vestígios, seja na imprensa do norte como do sudeste, aonde veio a falecer por volta de $1895 .^{47}$ Com isso, consideramos que existem mais questões abertas do que respostas sobre o republicano e abolicionista, Romualdo Alves de Oliveira.

\section{Algumas considerações}

Por meio da reconstituição da vida de Romualdo e do cruzamento das informações dos registros acima analisados, pudemos reconstruir partes de um quebra cabeça, no qual figura a importância desse republicano abolicionista engajado em múltiplas causas sociais e políticas de sua época, orientadas por um regime monárquico que a todo instante insista em demarcar as desigualdades sociais fundadas com as hierarquias e num regime escravista. $\mathrm{O}$ próprio nome de Romualdo por nós achados em jornais e nos processos crimes por ele assinado é uma chave importante para encontrá-lo em seu tempo e espaço. Nas fontes usadas, seu nome aparece por vezes como descrito por "Romualdo Alves de Oliveira", "R. A. d'Oliveira", "Romualdo Alves d'Oliv" e "Romualdo de Oliveira".

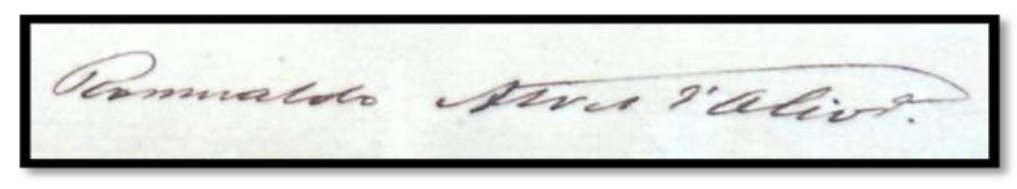

Figura 6 - Assinatura de Romualdo Alves de Oliveira. Comarca de Recife - 1879 -Processo Civil - Processo de Liberdade da escrava Silvéria.

A assinatura de Romualdo nos indica duas coisas: primeiro era homem letrado e, segundo, seu nome registrado num processo de liberdade nos indica que sua atuação enquanto advogado era reconhecido, sem mesmo ter formação de bacharel em direito. Seu projeto de uma república no Brasil não era uma perspectiva isolada. No decorrer das grandes transformações operadas no contexto do Império brasileiro, jornais republicanos de várias províncias 
passaram a difundir esse ideário marcado por mudanças políticas do governo. Pode parecer incomum para a historiografia, porém, a pesquisa aqui realizada sobre os republicanos antiescravistas comprova que existiram sujeitos históricos anônimos que nem sequer foram reconhecidos em vida, mas em sua militância política atuaram em diferentes frentes para que o princípio democrático em que acreditavam se tornasse no tempo presente uma realidade. $\mathrm{Na}$ construção desses horizontes de expectativas por uma sociedade com menos desigualdade tinham que encontrar dissoluções a todo tempo.

A produção impressa desses republicanos históricos que discorreram sobre o problema da escravidão falta ainda serem apresentadas numa pesquisa conjunta que der conta da atuação antiescravista desses sujeitos que dela participaram politicamente, em diferentes espaços, agências, sonhos, contradições, assim como se mobilizaram no processo que desembocou na estruturação do partido republicano e, quiçá, no protagonismo de seus membros na luta pela concretização da abolição da escravidão brasileira. Romualdo Alves de Oliveira é apenas um desses personagens que demonstram que os republicanos, anterior mesmo à formação do Partido Republicano nas diversas regiões do Brasil Império, atrelavam suas prerrogativas de liberdade e de governo democrático na luta contra a escravidão. A produção impressa desenvolvida por esse intelectual é significativa e nos indica que é preciso relativizar quando o assunto se trata de desqualificá-los.

É comum a historiografia oitocentista impor à pecha de que os republicanos brasileiros não trataram ou sequer foram favoráveis a discutir o problema do regime de escravidão. Resgatar as histórias de agentes politicamente engajados a este tema, se mostrou como o ideário antiescravista é presente nos impressos republicanos, como também de suas participações nos movimentos sociais que mobilizaram as ruas da cidade. Investigar o trajeto percorrido por Romualdo Alves e de seus impressos, nos mostrou ser um bom caminho metodológico, pois existem documentações por eles produzidas, que comprovam que republicanos se atentaram para a questão escravista. O reconhecimento e valorização a esses tribunos não deve ser medido, apenas, por estarem encampando suas lutas nos diversos contextos que negam sua presença, mas também por obrarem pelos direitos políticos do povo pela instauração de uma forma de governo baseada em princípios democráticos, sejam elas através de seus jornais, como nas passeatas, meetings e também na organização de sociedades políticas das mais diversas.

No Brasil oitocentista, os republicanos históricos recifenses e sua imprensa exerceram papéis indispensáveis na configuração do partido republicano e foram vitais para formação 
dos ideários políticos que atualmente se encontram corporificadas no nosso regime constitucional, revelando uma face pouco levada em conta pela historiografia das últimas décadas da abolição. Em síntese, como podemos acompanhar os republicanos recifenses empenharam-se na formação de uma cultura política democrática na busca de um debate abolicionista, cujo movimento social contemplou várias agências e sujeitos históricos, desde os escravizados, monarquistas e até mesmo republicanos históricos que não mediram esforços em postular em seus jornais contra o regime escravista. Ser republicano era não aceitar a escravidão. Essa era concepção de Romualdo Alves e de tantos outros homens e mulheres brasileiros que acreditavam e atuaram politicamente na defesa de um país mais justo e democrático, já na segunda metade do século XIX, até o fim da instituição escravista em 13 de maio de 1888. Por ora, esses e outros caminhos que momentaneamente apresentamos este trabalho.

\section{Notas}

${ }^{1}$ Goiânia tinha porto fluvial, chegando a capitanear um dos maiores pólos de concentração comercial durante o
período do Brasil Colônia, em seus entrepostos escoava a produção de pau-brasil e cana-de-açúcar. No século
XIX com a modernização dos portos, serviu entreposto comercial que ligava Recife e Olinda e outras comarcas
da província. Cf. PINTO, O. Velhas histórias de Goiânia. Rio de Janeiro: Vecchi, 1968; SOUZA, S. M. Goiânia, a nossa pequena Pátria: Recife: Luci Artes Gráficas Ltda., 2005.

${ }^{2}$ Sobre Romualdo Alves de Oliveira ver, Paula Cavalcanti. Eça de Queiroz: agitador no Brasil. São Paulo, $4^{\text {a }}$ edição revista e ampliada. Recife, Cepe, 2015, p. 62. Nasceu em Tejucupapo, fazia parte da comarca de Goiânia, interior de Pernambuco. Em 1855, quando grassava a epidemia de cólera em Pernambuco, Romualdo escreveu no seu Brado do Povo "Ali onde nasci pela primeira vez vi a luz do dia, e onde tenho alguns parentes, muito sinto se for devastado pelo terrível viajante - o cólera-morbo". Apud, CALVACANTI, p. 162.

${ }^{3}$ Sacramento Blake. Diccionário Bibliográphico, Imprensa Nacional, Rio de Janeiro, v. 7, 1970, p. 153.

${ }^{4}$ Encontramos o nome de Joaquim Alves de Oliveira, pai de Romualdo Alves, na seção de "Notícias Marítimas" no jornal mais antigo da província. Provavelmente, era envolvido com o comércio exportador de farinha de Pernambuco. Diário de Pernambuco. 21, nov. 1829. p. 4.

${ }^{5}$ No decorrer da pesquisa, encontramos os três filhos de Romualdo Alves: Josepha Águeda Felisbella Mercedes de Oliveira e D. Jovelina Alves de Oliveira e Romualdo Alves de Oliveira Filho Sobre as filhas, Cf. Discursos que deviam ser proferidos na sessão magna do Club Abolicionista. pp. 10-12. Tipografia Jornal do Recife, 1882. APEJE, R.1438, Cx.6. 0484 e Diário de Pernambuco. 17, fev, 1882. p. 8; Curioso notar que Romualdo Filho, está presente na seção "Movimento do Porto". Nesse documento consta sua chegada à cidade do Rio de Janeiro pelo paquete Espírito Santo, período esse em que seu pai, já se encontrava residindo na capital federal. Cf: Jornal do Comércio. 31 de mar, 1883, p. 3.

${ }^{6}$ DORNELAS, Câmara, Bruno Augusto. O "retalho" do comércio: a política partidária, a comunidade portuguesa e a nacionalização do comércio a retalho, Pernambuco 1830- 1870. Recife: Universidade Federal de Pernambuco, CFCH. Programa de Pós-Graduação em História, 2012. p. 22.

${ }^{7} \mathrm{Na}$ comarca de Goiânia, um movimento sedicioso se dera entre pernambucanos contra portugueses. Tal acontecimento desembocou em denúncias na folha do Diário de Pernambuco do dia 7, cuja seção "Editoriais", protestava-se contra o espancamento de portugueses "insultados e agredidos em suas próprias casas e nas ruas mais públicas daquela cidade". No mesmo dia, o Jornal do Recife noticiava "Pessoa chegada ontem pela manhã de Goiana, donde partira anteontem às 4 horas da tarde, disse-nos que continuava ainda ali o mesmo estado de coisas". As origens do movimento sedicioso ganhou repercussão das mais variadas, tendo inclusive figuras do porte da literatura como Franklin Távora que se envolveu no embate, denunciando na imprensa conservadora do Diário o "canibalismo de Goiana", ante aos entraves contra os portugueses. Desses atritos, se sobressaí às 
notícias veiculadas do impresso A Verdade que denunciou o posicionamento de "homens que, pela sua posição literária e científica, excluem toda presunção de preconceitos retrógados, e pelo contrário dão lugar a se presumir da sua parte a mais completa má fé". Transcrevendo a edição da folha maçom A Verdade, o Jornal do Recife justificava quais eram os motivos reais que se devera aos patriotas dessa comarca se insurgir contra os portugueses: foi mediante a publicação feita por escritores portugueses contra os guianenses, cujo o título Farpas ironizava-os. Na publicação de 10 de agosto de 1872, ao remeter carta à redação do Jornal do Recife, justificou o procedimento de seus “irmãos, defendendo-os do injusto epíteto de Canibais”. Cf. Para análise do conflito, ver as matérias publicadas no Jornal do Recife, edição de 7 e 10 de agosto de 1872. Sobre a repercussão desse conflito na Inglaterra, Cf: Eco Americano, edição de 15 de outubro de 1872, Londres; Do Rio, o Ministro do Império João Alfredo Correia de Oliveira, goianense e chefe político do Partido Conservador, registrou a comunicação dos fatos: "Acuso o recebimento da carta confidencial que com a data de 9 do corrente mês dirigiu-me V. Excia. a respeito dos fatos desagradáveis que ultimamente ocorreram na cidade de Goiana (...)”. Essa última correspondência foi registrada por Paula Calvacanti, na nota de rodapé 15, op. cit, p. 161. Diante de tais fatos arrolados, a importância que Romualdo Alves assumiu na esfera pública em defesa de seus conterrâneos no Recife foi fundamental. Reconhecido como publicista de jornais republicanos, nesse ano de 1872 fez circular $O$ Comércio a Retalho (1872-1875). Impresso publicado no Recife com pequenas interrupções, até 1875 . $O$ Comércio exerceu enorme influência nas lutas contra o predomínio português no comércio interno. Na Base da CEPE é possível consultar quatros números.

${ }^{8}$ CALVACANTI, Paulo. Eça de Queiroz, um agitador no Brasil. Companhia Editora Nacional, São Paulo, 1959. p.149; Também o estudo clássico sobre os republicanos BOEHRER, George C.A. Da Monarquia à República: História do Partido Republicano do Brasil (1870-1889). Rio de Janeiro: Ministério da Educação e Cultura, 1954.

${ }^{9}$ Remetemos aos espaços históricos: Instituto Arqueológico, Geográfico e Histórico de Pernambuco (IAGHP), Memorial da Justiça de Pernambuco (MJPE), Arquivos da Biblioteca Pública Jordão Emerenciano (APEJE) como de seu prédio Anexo - e, os presentes nos dados da base do Arquivo da Biblioteca Nacional e na base digital da Companhia Editora de Pernambuco (CEPE). Para maiores informações sobre os republicanos no Brasil Império e seus documentos históricos, Cf: AMARAL LAPA, José Roberto Do. História Política Da República. Editora Papirus, 1990.

${ }^{10}$ O Echo Pernambucano: Liberdade, União e Pátria. 3 jun, 1851. O caso foi levado pela imprensa para o público recifense está informado sobre as arbitrariedades que ocorriam na comarca. Os portugueses são mencionados, um se chamava Antonio Pinheiro, e o outro Ernesto Charuteiro. O “escritor de Goiânia” vinha a público destacar as arbitrariedades realizadas sob a administração do delegado Antônio Francisco e o subdelegado Francisco de Paula Noberto de Andrade pela comarca de Pajeú das Flores, ambos pertencentes ao Partido dos Gabirus. Os brasileiros mencionados são B. da Veiga e José Nunes.

${ }^{11}$ CAVANI, Suzani Ação, Reação e Transação: A Sociedade Liberal Pernambucana (1851-1861). Clio. Série História do Nordeste (UFPE), Recife, v. 1, n.17, 1999.

12 Em fevereiro de 1848, destronara-se Luís Felipe da França. Aboliram-se as instituições monárquicas e proclamara um regime republicano. O impacto desse evento, conhecido como a primavera dos povos chegou a todo Ocidente, inclusive no Brasil. De acordo com Amaro Quintas, ao ler Wanderley Pinho em sua obra "Cotegipe e seu Tempo" conta-se que o imperador estava "no teatro quando soube haverem chegado jornais com a narrativa da revolução contra Luís Filipe. Mandou logo à casa de Otaviano buscar essas folhas e, recebidas elas, "um pouco alterado", retirou-se para dentro do teatro e foi lê-las; dizem que agitado". Ver, (1937, p.308, apud PINHO, 1937, p. 140). Para maiores informações, Cf. QUINTAS, Amaro. "O espírito QuaranteHuitard e a Revolução Praieira". In: Revista de História. 19(40), 1959. pp. 303-324.

${ }^{13}$ Doc. In: Autos do Inquérito da Insurreição Praieira, Recife: 1849; Brasília: Senado Federal, 1979, pp. $107-$ 109.

${ }^{14}$ CASTRO, Paulo Pereira de. A "experiência republicana", 1831- 1840. In: HOLANDA, Sérgio Buarque de; CAMPOS, Pedro Moacyr (orgs.). História geral da civilização brasileira, t. II, v.2: In: O Brasil monárquico: dispersão e unidade. $5^{\text {a }}$ ed. São Paulo: Difel, 1985

${ }^{15}$ MATTOS, Ilmar Rohloff de. O tempo Saquarema. São Paulo: HUCITEC; Brasília: INL, 1987.

${ }^{16}$ BIGNOTTO, Newton. (Org.). Matrizes do Republicanismo. 1. ed. Belo Horizonte: UFMG, 2013.

17 BIGNOTTO, Newton. op. cit., In: STARLING, H. pp. 231-314.

${ }^{18}$ Como os advogados e jornalistas políticos Antônio Borges da Fonseca (1808-1872) e Afonso Albuquerque de Melo (1811- 1869), ambos os redatores conhecidos por divulgarem suas ideias republicanas e emancipacionistas na província pernambucana através do jornal A Revolução de Novembro. Ao primeiro coube-lhe presidir no ano de 1859 à Sociedade de Socorros Mútuos da Emancipação dos Cativos e ao segundo, presidir a Sociedade Abolicionista de Desterro/SC (hoje Florianópolis); outro republicano histórico e não menos importante é o João de Barros Falcão d'Albuquerque Maranhão (1807-1881), que possui destaque por sua vasta produção de jornais de 
orientação republicana ainda pouco reconhecidos pela historiografia, e por último, o professor negro de primeiras letras João Ciriaco da Silva, redator d'O Povo. Sobre Afonso de Albuquerque de Melo, consultar: Sacramento Blake. Diccionário Bibliográphico, Imprensa Nacional, Rio de Janeiro, Rio de Janeiro Tipografia Nacional, v. 1, 1970, p. 11. No sítio Memória Política há maiores informações sobre esse político. Consultar: Afonso d'Albuquerque e Melo. Acesso, 27, nov, 2019.

19 As citações se encontram, respectivamente em: MOREIRA, Luciano da Silva. Imprensa e política: espaço público e cultura política na província de Minas Gerais (1828-1842). Dissertação (Mestrado em História) - Faculdade de Filosofia e Ciências Humanas, Universidade Federal de Minas Gerais, Belo Horizonte, 2006. p. 12.

${ }^{20}$ HOFFNAGEL, Marc J. From Monarchy to Republic in Northeast Brazil: the Case Pernambuco, 18681895. Tese de Doutorado, Indiana. Indiana University, 1975.

${ }^{21}$ BRAGA, Flávia Bruna Ribeiro da Silva. "Ditadura", Abolição e República: a propaganda da geração positivista em Pernambuco (1875-1889). Dissertação de Mestrado - Universidade Federal de Pernambuco, CFCH. Programa de Pós-Graduação em História, Recife, 2017.

${ }^{22}$ É o caso do republicano histórico Dr. João de Barros Falcão de Albuquerque Maranhão, conhecido vulgarmente pelo apelido de Barros Vulcão. Natural de Pernambuco, bacharelou-se em Ciências Jurídicas e Sociais, pelo Curso Jurídico da cidade de Olinda em 1837. Barros Falcão era membro da Sociedade Federal, fez publicação criticando ao Sr. Montezuma (futuramente, Visconde de Jequitinhonha), exposta no Diário de Pernambuco, rogando-lhe para o mesmo deixar de comparecer às sessões da dita Sociedade por conta de seus "asnáticos discursos" que realizava, obrigando seus sócios a se retirarem. Cf. Diário de Pernambuco. 31 de julho, 1833, p. 3. Como republicano, tentou pleitear cargo a deputado, em diversos momento, primeiramente o vemos, em 1843. Concorreu a eleição das seguintes comarcas: Colégio do Cabo, Olinda e do Colégio Eleitoral de Pajeú das Flores, obtendo respectivamente três, nove e onze votos, não vencendo o pleito em nenhuma delas. Cf. $O$ Diário Novo, 1/2/13 set, 1843, p. 2; Ano seguinte, em 1844, concorreu eleição para deputado no Colégio Eleitoral de Rio Famoso, obtendo 16 votos. Cf: Diário de Pernambuco. 08, nov, 1844, p. 1; Por volta de 1847 concorreu a eleição para Deputado à Assembleia Geral Legislativa Provincial. Cf. O Diário Novo. 11/16 Dez, 1847, p. 2. Infelizmente, em nenhuma delas logrou sucesso.

${ }^{23}$ Essa informação pode ser confirmada nos registros que Luiz do Nascimento catalogou em sua monumental obra "História da Imprensa em Pernambuco", especificamente, nos volumes 4 e 5.Ver, NASCIMENTO, Luiz do. História da imprensa de Pernambuco (1821-1954), 9 v. Recife: UFPE, 1969. Sabemos ainda que Romualdo de Oliveira antes de iniciar carreira na imprensa pernambucana, de acordo com Paulo Cavalcanti, este republicano "Antes de iniciar como diretor de jornal, colaborara em muitos periódicos recifenses, como o Eco Pernambucano, Nova Era, O Povo, etc”. CAVALCANTI, Paulo. Op. cit. 2015, p. 161.

${ }^{24}$ Criada no final do ano de 1859, a fundação da Associação de Socorros Mútuos e Lenta da Emancipação dos Captivos (1859-1862) foi um dos primeiros órgãos associativos emancipacionista na província, cujo objetivo era libertar escravizados. Esse movimento, organizado por grupos de republicanos pertencentes à geração "Quarante-huitard". Esta categoria se deveu ao fato do historiador pernambucano Amaro Quintas atribuir a essa geração a grupos de escritores públicos que disseminaram os ideais revolucionários da segunda república francesa na região pernambucana, justamente num contexto político em que acontecia o movimento praieiro e, pelo que sabemos, posteriormente a derrota dos revolucionários. Note-se que a grande maioria de seus membros dirigentes, nos primeiros anos, fora coordenada por republicanos pernambucanos. Destaque-se: Antônio Borges da Fonseca, seu primeiro presidente, Luiz Ciríaco da Silva que ocupou o cargo de primeiro tesoureiro e Romualdo Alves de Oliveira que no dia da instalação da dita da ASMLEC coube-lhe o papel de recitar uma poesia de cunho abolicionista e registrar os acontecimentos desse evento no seu periódico republicano $O$ Democrata (1857-1859). Para compreensão da geração Quarante-huitard, ver: QUINTAS, Amaro. "O espírito Quarante-Huitard e a Revolução Praieira”. In: Revista de História. 19(40): 303. dez. 1959; CHACON, Vamireh. História das ideias socialistas no Brasil. $2^{\circ}$ Ed., Civilização Brasileira, Rio de Janeiro, 1981. Cf. A Tesoura, 16, set, 1859. p. 2; O Democrata, 14 set, 1859. p. 2.

${ }^{25}$ Cf. ENTRE REALIDADES E DISSOLUÇÕES: Emancipação, Imprensa republicana e abolicionismo em Pernambuco (1848-1875). Dissertação (mestrado) - Universidade Federal Fluminense, Niterói, 2020, capítulo I, pp. 40-49.

${ }^{26}$ Os referidos jornais são: O Artista Pernambucano (1853), O Brado da Miséria (1853), O Brado do Povo (1854-1856), O Democrata (1857-1859) A República (1871), República Federativa: Órgão do Clube Republicano no Recife (1872-1873), A Luz: Periódico Republicano (1873-1875) e O Comércio a retalho (1876). Todos esses periódicos foram por nós acessados no APEJE.

${ }^{27}$ O Jornal O Democrata encontra-se disponível apenas nas dependências da Biblioteca Pública do Estado de Pernambuco Jordão Emerenciano (APEJE). Divididos em 4 séries, o mesmo circulou entre setembro de 1857 a setembro de 1859. APEJE, DJ-23, D-6. 
${ }^{28}$ A República Federativa, n. 1-3.

${ }^{29}$ A Luz: periódico republicano. 04. jun. 1873. p. 2

${ }^{30}$ A Luz: periódico republicano. 19. jun. 1873. p. 3

${ }^{31}$ Essa atuação enquanto rábula pode ser encontrado nos impressos do Diário de Pernambuco e Jornal do Recife. Cf, Diário de Pernambuco (1860-1879), Jornal do Recife (1860-1883).

${ }^{32}$ Metáfora teatral que José Murilo de Carvalho justifica para caracterizar o Império brasileiro. Esse tipo de análise política se encontra no segundo capítulo da obra que originalmente é a Tese de Doutorado em Ciência Política. Cf, CARVAlHO, José Murilo. A Construção da Ordem: a elite política imperial; Teatro das Sombras: A política imperial. 2.ed. Rio de Janeiro: UFRJ, Relume-Dumará, 1996.

${ }^{33}$ Sobre esse periódico, só tivemos acesso ao número doze, único número que podia ser manuseado no APEJE, publicado no dia 16 de setembro de 1856. NASCIMENTO, Op. cit. vol. 5. p.56.

${ }^{34}$ Diário de Pernambuco, 3 out. 1879, p.3.

${ }^{35}$ Obra crucial para se compreender como atuava os advogados no século XIX, é da historiadora Keila Grinberg. Cf, GRINBERG, Keila, O fiador dos brasileiros- cidadania, escravidão e direito civil no tempo de Antonio Pereira Rebouças, Rio de Janeiro: Civilização Brasileira, 2002.

${ }^{36}$ Gazeta da Tarde, 04, Out, 1884, p. 2

${ }^{37}$ SANTOS, Cláudia. Por uma história republicana da abolição. Rio de Janeiro: (em fase de elaboração), especificamente, o capítulo III [seção 3.2], 2020.

${ }^{38}$ MELO, Maria T. Chaves de. A República consentida: cultura democrática e científica do final do Império. Rio de Janeiro: FGV/Edur, 2007.

${ }^{39}$ ARAÚO, Rodrigo Cardoso Soares de. Pasquins: Submundo da imprensa na Corte Imperial (1880-1883). 1 edição, Editora Multifoco, Rio de Janeiro, 2012.p. 229.

${ }^{40}$ CARVALHO, José Murilo de. História intelectual no Brasil: a retórica como chave de leitura. Topoi, Rio de Janeiro, v.1, n.1, 2000. pp. 123-152.

${ }^{41}$ O Liberal, 25 mai. 1873 , p. 4.

${ }^{4}$ O Clube Tiradentes, segundo José Murilo de Carvalho foi criado em 1882 por republicanos abolicionistas contra a colocação da estátua de D. Pedro I no local do enforcamento de Tiradentes. Tal insatisfação configurouse na dedicação destes republicanos, sobretudo na capital do Império e em São Paulo, à tarefa de recuperar a imagem do inconfidente. Cf: CARVALHO, José Murilo de. O Código Tiradentes. Estudos Avançados, São Paulo, v. 32, n. 92, 2018. p. 143.

${ }^{43}$ Diário de Notícias, 23 abr. 1886, p. 1.

${ }^{44} \mathrm{O}$ jornal informa que o sr. Álvaro da Costa Dias era seu genro.

${ }^{45}$ Essa informação pode ser encontrada no Diário de Notícias 16 nov, 1888, p. 1 e 25, nov, 1888. p. 1; Ver também na Gazeta de Notícias, 24, nov. 1888, p. 1.

${ }^{46}$ Gazeta de Sapucaia, 22, nov, 1888.

${ }^{47}$ Romualdo Alves veio a falecer na Capital Federal no dia 13 de janeiro de 1895. Foi enterrado no Cemitério São João Batista, localizado no bairro Botafogo, Zona Sul do Rio de Janeiro.

\section{Referências}

AMARAl laPA, José Roberto Do. História Política Da República. Editora Papirus, 1990.

ARAÚO, Rodrigo Cardoso Soares de. Pasquins: Submundo da imprensa na Corte Imperial (18801883). 1 edição, Editora Multifoco, Rio de Janeiro, 2012.

BRAGA, Flávia Bruna Ribeiro da Silva. "Ditadura", Abolição e República: a propaganda da geração positivista em Pernambuco (1875-1889). Dissertação de Mestrado - Universidade Federal de Pernambuco, CFCH. Programa de Pós-Graduação em História, Recife, 2017.

BLAKE, Sacramento. Diccionário Bibliográphico, Imprensa Nacional, Rio de Janeiro, v. 7, 1970.

BIGNOTTO, Newton. (Org.). Matrizes do Republicanismo. 1. ed. Belo Horizonte: UFMG, 2013. 
BOEHRER, George C.A. Da Monarquia à República: História do Partido Republicano do Brasil (1870-1889). Rio de Janeiro: Ministério da Educação e Cultura, 1954.

CARVALHO, José Murilo. A Construção da Ordem: a elite política imperial; Teatro das Sombras: A política imperial. 2.ed. Rio de Janeiro: UFRJ, RelumeDumará, 1996.

CARVALHO, José Murilo. História intelectual no Brasil: a retórica como chave de leitura. Topoi, Rio de Janeiro, v.1, n.1, 2000.

CARVALHO, José Murilo. O Código Tiradentes. Estudos Avançados, São Paulo, v. 32, n. 92, 2018.

CAVALCANTI, Paula. Eça de Queiroz: agitador no Brasil. São Paulo, $4^{\mathrm{a}}$ edição revista e ampliada. Recife, Cepe, 2015

CAVANI, Suzani Ação, Reação e Transação: A Sociedade Liberal Pernambucana (1851-1861). Clio. Série História do Nordeste (UFPE), Recife, 1999.

DORNELAS, Câmara, Bruno Augusto. O "retalho" do comércio: a política partidária, a comunidade portuguesa e a nacionalização do comércio a retalho, Pernambuco 1830- 1870. Recife: Universidade Federal de Pernambuco, CFCH. Programa de Pós-Graduação em História, 2012

GRINBERG, Keila, $O$ fiador dos brasileiros- cidadania, escravidão e direito civil no tempo de Antonio Pereira Rebouças, Rio de Janeiro: Civilização Brasileira, 2002.

HOFFNAGEL, Marc J. From Monarchy to Republic in Northeast Brazil: the Case Pernambuco, 1868-1895. Tese de Doutorado, Indiana. Indiana University, 1975.

MELO, Maria T. Chaves de. A República consentida: cultura democrática e científica do final do Império. Rio de Janeiro: FGV/Edur, 2007.

MATTOS, Ilmar Rohloff de. O tempo Saquarema. São Paulo: HUCITEC; Brasília: INL, 1987.

MOREIRA, Luciano da Silva. Imprensa e política: espaço público e cultura política na província de Minas Gerais (1828-1842). Dissertação (Mestrado em História) - Faculdade de Filosofia e Ciências Humanas, Universidade Federal de Minas Gerais, Belo Horizonte, 2006.

NASCIMENTO, Luiz do. História da imprensa de Pernambuco (1821-1954), 9 v. Recife: UFPE, 1969.

PINTO, O. Velhas histórias de Goiânia. Rio de Janeiro: Vecchi, 1968

QUINTAS, Amaro. "O espírito Quarante-Huitard e a Revolução Praieira". In: Revista de História. 19(40), 1959.

SOUZA, S. M. Goiânia, a nossa pequena Pátria: Recife: Luci Artes Gráficas Ltda., 2005. 